\title{
Application of Equivalent Simplified Calculation Model of Isolated Structure in Super High-rise Building
}

\author{
Yingjun Wang ${ }^{1 *}$, Tianli Chen ${ }^{2}$ \\ ${ }^{1}$ Department of Civil Engineering, Xuchang University, Xuchang, Henan,China \\ ${ }^{2}$ Department of Architectural Engineering, Shengda Trade Economics \& Management College of \\ Zhengzhou, Zhengzhou, Henan, China
}

\begin{abstract}
:
In this paper, the application of equivalent simplified calculation model of isolated structure in super high-rise building is studied. In this paper, the characteristics of isolation structures with different height width ratio are analyzed, and the relationship curve between the limit value of height width ratio of isolation structure and the distance of isolation support is established. From the curve, we can estimate the limit height of the isolated structure when the bearing does not produce tensile stress under different seismic intensities. This paper also analyzes the influencing factors of the height width ratio limit, and puts forward the method of increasing the height width ratio limit. In this paper, a vertical stiffness correction model of isolation bearing is proposed. Compared with the shaking table test results and time history analysis, the modified model can truly reflect the mechanical properties of the isolation bearing.
\end{abstract}

Keywords: Super High Rise Building, Wooden Structure, Isolation Design, Strength Check.

\section{INTRODUCTION}

After more than 30 years of development in China, seismic isolation technology has made a series of achievements in the field of applied basic theory, formed a relatively systematic theory, and began to be applied to the engineering field in the 1980s [1-2]. However, compared with the more mature concrete theory, the isolation technology is only at the department level, especially the high-rise isolation technology, and there are many problems to be solved [3-6]: (1) Performance optimization of isolation device and research and development of new isolation device. (2) Selection of seismic input for the design of isolated structures: amplitude, spectrum characteristics, duration selection, selection of recorded seismic waves and site influence. (3) Vibration characteristics of high-rise isolation structure, tensile characteristics of isolation layer, 
Article History: Received: 28 October 2021 Revised: 05 December 2021 Accepted: 10 January 2022 Publication: 28 February 2022

Anti overturning. Countermeasures of isolation structure, etc. In view of the above technical problems of high-rise isolation, this paper will focus on the limit of height width ratio of highrise isolation structure, the optimization of isolation layer parameters and the seismic response prediction of high-rise isolation structure.

\section{ANALYSIS OF HEIGHT WIDTH RATIO LIMIT AND INFLUENCE LAW OF HIGH-RISE ISOLATION SYSTEM}

1. Influence of story deformation and high-order vibration modes of isolated structures with different height width ratio

The characteristics of isolation structures with different height width ratio are the same as those of ordinary isolation structures [7-8]. The safety of isolation structure design is evaluated by analyzing the displacement response of isolation layer, interlayer deformation of superstructure, maximum acceleration response and interlayer shear force. With the increase of the aspect ratio, the period of the isolated structure, the deformation curve between floors, the influence of the higher-order vibration mode, the overturning moment of the structure and the probability and magnitude of the tensile stress of the isolated support will also change [9].

The isolation principle of high aspect ratio isolation structure is similar to that of multi-layer isolation structure. The deformation is mainly concentrated in the isolation layer, the superstructure basically maintains the translational state, and the interlayer deformation of the structure is basically unchanged. It shows that the isolation mechanism of isolation structures with different height width ratio is the same, and the deformation is mainly concentrated in the isolation layer [10-12]. In addition, with the increase of aspect ratio, the mass of superstructure increases, the area of isolation support and the diameter of lead core increase, and the horizontal stiffness of isolation layer and the yield stress of lead core also increase. The displacement of the isolation layer of the isolation structure with large aspect ratio is higher and the displacement of the aspect ratio is smaller, which also shows that the damper plays a good role in restraining the displacement of the isolation layer [13].

Taking the inter story displacement angle of the first floor of the structure as an example, the influence of higher-order vibration modes on the isolated structure is illustrated, as shown in Table 1.

TABLE I. Influence of high-order vibration modes on isolated structures

\begin{tabular}{|c|c|c|c|c|c|c|c|c|c|}
\hline $\begin{array}{c}\text { HEIGHT } \\
\text { TO } \\
\text { WIDTH } \\
\text { RATIO }\end{array}$ & 3 & 6 & 9 & 12 & 15 & 18 & 21 & 24 & DIFFERENCE(\%) \\
\hline
\end{tabular}


January-February 2022 Page No.115-123

Article History: Received: 28 October 2021 Revised: 05 December 2021 Accepted: 10 January 2022 Publication: 28

February 2022

\begin{tabular}{|l|l|l|l|l|l|l|l|l|l|}
1 & $1 / 680$ & $1 / 681$ & $1 / 682$ & $1 / 682$ & $1 / 682$ & $1 / 682$ & $1 / 682$ & $1 / 682$ & 2.34 \\
\hline 3 & $1 / 176$ & $1 / 157$ & $1 / 166$ & $1 / 165$ & $1 / 165$ & $1 / 165$ & $1 / 165$ & $1 / 165$ & 6.28 \\
\hline 5 & $1 / 197$ & $1 / 183$ & $1 / 215$ & $1 / 236$ & $1 / 237$ & $1 / 239$ & $1 / 239$ & $1 / 239$ & 21.3 \\
\hline 7 & $1 / 309$ & $1 / 310$ & $1 / 234$ & $1 / 234$ & $1 / 217$ & $1 / 213$ & $1 / 208$ & $1 / 208$ & 32.6 \\
\hline
\end{tabular}

It can be seen from the table that with the increase of structure height and aspect ratio, the structure is more and more affected by high-order vibration modes. For the structure with aspect ratio of 1 , the first three modes of inter story displacement angle can be stable, while for the structure with aspect ratio of 7, the 21st mode can be stable, and the difference of inter story displacement angle between low-order mode and high-order mode can reach $32.6 \%$. It shows that the influence of high-order mode components can not be ignored in high-rise isolated structures, especially for high-rise structures with obvious characteristics with large structural stiffness and shear walls.

2. Bearing spacing

Keep the parameters of the superstructure unchanged, adjust the stiffness of the upper roof of the isolation layer to infinity [14]. By changing the number of single-sided isolation bearings and ensuring that the horizontal stiffness of isolation bearings remains unchanged, the peak overturning moment of the structure gradually increases with the increase of the number of isolation bearings, as shown in Table 2 .

TABLE II. Overturning moment of structure under different support spacing

\begin{tabular}{|c|c|c|c|c|c|c|c|}
\hline $\begin{array}{c}\text { EARTHQUAKE } \\
\text { INTENSITY }\end{array}$ & $\mathbf{3 . 7 5}$ & $\mathbf{4 . 3}$ & $\mathbf{5}$ & $\mathbf{6}$ & $\mathbf{7 . 5}$ & $\mathbf{1 0}$ & $\mathbf{1 5}$ \\
\hline 7.5 RARE CASES & 5870 & 7807 & 7833 & 9053 & 9511 & 10456 & 11212 \\
\hline 8 DEGREES RARE & 6722 & 8490 & 8693 & 10680 & 11350 & 11702 & 12036 \\
\hline 8.5 RARE CASES & 7738 & 9086 & 9821 & 12777 & 13401 & 13959 & 14337 \\
\hline
\end{tabular}

In the design process of isolated structure, on the premise of ensuring the use function, the structural form of large column spacing is adopted. On the one hand, the increase of bearing spacing can improve the height width ratio limit of the structure. On the other hand, the increase of bearing spacing will also increase the diameter of isolation bearing, which can increase the deformation limit of isolation layer. In addition, because the isolation bearing in the model is selected according to the maximum axial force of the column, the bearing at the corner column is too large. If the bearing is selected according to the corresponding surface pressure at the bottom of the column, the limit value of height width ratio can be further improved. 
Article History: Received: 28 October 2021 Revised: 05 December 2021 Accepted: 10 January 2022 Publication: 28

\section{SEISMIC RESPONSE ANALYSIS OF ISOLATED STRUCTURES BASED ON ENERGY PRINCIPLE}

1.Simplified calculation model of mode decomposition response spectrum method

The isolation structure is arranged with isolation layers on the foundation and superstructure. The stiffness of the isolation layer is much less than that of the superstructure. During earthquake, the deformation is mainly concentrated in the isolation layer, and the superstructure is in translational state, which can be regarded as a rigid body. Therefore, the simplified multi particle system calculation model of multi-storey isolation structure building is simplified into the calculation model of single particle system and the restoring force model of isolation layer according to the translation assumption of superstructure, such as. Indemnificatory housing refers to the housing with limited standards, prices or rents provided by the government for low - and middle-income families with housing difficulties. It is generally a small-scale house type and large-scale construction, which is very suitable for the implementation of standardized design, industrialized application of component production and integration of construction and decoration. Housing industrialization is the manufacturing of housing by large-scale industrialized production mode, so as to improve production efficiency and overall quality, and effectively reduce building energy consumption, which is very consistent with the construction requirements of indemnificatory housing.

The mass of the superstructure of the single mass point calculation model is expressed in Peng. The stiffness and damping of the isolation layer are taken as the stiffness and damping. The motion equation of the system is:

$$
m \ddot{x}_{s}+c \dot{x}_{s}+k x_{s}=-m \ddot{x}_{g}
$$

The isolation structure with regular shape can be solved by the equivalent lateral force method, and the horizontal stiffness $\mathrm{k}$ and effective damping ratio $\xi$ of the isolation layer are calculated according to formula (2).

$$
\begin{gathered}
k=\sum_{i=1}^{n} k_{i} \\
\xi=\frac{\sum_{i=1}^{n} k_{i} \xi_{i}}{k}
\end{gathered}
$$

Where, $\mathrm{k}$ is the sum of the effective stiffness of all isolation bearings and damping devices of the isolation layer;

$k_{i} \xi_{i}$ is the horizontal effective stiffness and effective damping ratio of a single isolation bearing or damping device; 
Article History: Received: 28 October 2021 Revised: 05 December 2021 Accepted: 10 January 2022 Publication: 28 February 2022

$\xi$ is the effective damping ratio of the isolation layer.

The effective stiffness of the isolation layer is used to calculate the basic period $\mathrm{T}$ of the single mass point system:

$$
T=2 \pi \sqrt{\frac{m}{k}}
$$

Standard value of total horizontal seismic action of structure:

$$
\begin{array}{r}
F_{c k}=\alpha_{1} G \\
\delta=\frac{F_{c k}}{k}=\frac{T^{2} g}{4 \pi^{2}}\left(\frac{T_{g}}{T}\right)^{\gamma} \eta_{2} \alpha_{\max }
\end{array}
$$

Where, $\alpha_{1}$ - horizontal seismic influence coefficient, $\alpha=\left(\frac{T_{g}}{T}\right)^{\gamma} \eta_{2} \alpha_{\max }$

$\mathrm{G}$ - representative value of gravity of superstructure.

The total horizontal seismic action calculated by the superstructure is distributed to each particle according to the formula:

$$
F_{i k}=\frac{G_{i} H_{i}}{\sum G_{j} H_{j}} F_{c k}
$$

Where, $F_{i k}$ is the standard value of horizontal seismic action acting on particles;

$\mathrm{G}_{\mathrm{i}}$ and $\mathrm{G}_{\mathrm{j}}$ are gravity representative values of particles I and $\mathrm{j}$ respectively;

$\mathrm{H}_{\mathrm{i}}$ and $\mathrm{H}_{\mathrm{j}}$ are the calculated heights of particles $\mathrm{I}$ and $\mathrm{j}$ respectively.

2.Earthquake response prediction based on energy principle

The analysis object of this paper is the structure with rubber bearing and lead damper in the isolation layer (lead rubber bearing can be regarded as natural rubber bearing and lead damper in parallel).

The energy equation of isolated structure under horizontal earthquake is as follows:

$$
E_{V}+E_{C}+E_{D}+E_{Y}=E_{I}
$$

Where, $\mathrm{E}_{\mathrm{V}}$ - Structural kinetic energy;

$\mathrm{E}_{\mathrm{C}}$ - damping energy dissipation of isolation layer;

$E_{D}$ - energy consumption of isolation bearing:

$\mathrm{E}_{\mathrm{Y}}$ - structural deformation energy;

$\mathrm{E}_{\mathrm{I}}$ - seismic input energy.

The main seismic energy is mainly dissipated by the isolation layer (isolation bearing and damper), ignoring the energy consumption of the superstructure. Therefore, the energy equation 
Article History: Received: 28 October 2021 Revised: 05 December 2021 Accepted: 10 January 2022 Publication: 28 February 2022

of isolated structure can be written as:

$$
W_{c}\left(t_{m}\right)+W_{p}\left(t_{m}\right)=E_{I}
$$

Among them, $\mathrm{E}_{\mathrm{I}}, W_{p}\left(t_{m}\right)$ and $W_{c}\left(t_{m}\right)$ respectively represent the input energy, the plastic strain energy of damper $t_{m}$ and the elastic strain energy of isolation bearing $t_{m}$. Equation (9) ignores the influence of kinetic energy, potential energy and damping energy consumption of superstructure. On the one hand, the calculation is simplified. On the other hand, the calculation results are partial to safety considerations. The above factors can be used as safety reserves in engineering design.

\section{PARAMETER ANALYSIS OF ISOLATION LAYER}

The isolation structure system consists of superstructure, isolation layer and substructure. In order to achieve the expected isolation effect, the isolation layer must have four basic characteristics: (1) it has large vertical bearing capacity and safely supports the superstructure; (2) With variable horizontal stiffness, the stiffness before yield can meet the requirements of wind load and micro vibration. When a strong earthquake occurs, its small post yield stiffness makes the isolation system into a flexible system, effectively separates the ground vibration and reduces the seismic response of the superstructure; (3) With horizontal elastic restoring force, the isolation system has the function of reset in earthquake; (4) It has sufficient damping and large energy dissipation capacity.

Under the condition that the area of isolation bearing remains unchanged, the restoring force characteristics of isolation layer are changed by changing the number of lead rubber isolation bearings in isolation layer, so as to obtain the optimal isolation effect.

TABLE III. Parameters of isolation bearing

\begin{tabular}{|c|c|c|c|c|}
\hline PARAMETER & RB500 & RB600 & LRB500 & LRB600 \\
\hline EFFECTIVE AREA (CM2) & 1879 & 2820 & 1886 & 2827 \\
\hline HORIZONTAL STIFFNESS (KN / MM) & 0.76 & 0.99 & $/$ & $/$ \\
\hline STIFFNESS BEFORE YIELD (KN / MM) & $/$ & $/$ & 10.075 & 13.182 \\
\hline POST YIELD STIFFNESS (KN / MM) & $/$ & $/$ & 0.775 & 1.014 \\
\hline YIELD FORCE (KN) & $/$ & $/$ & 62.6 & 90.2 \\
\hline
\end{tabular}

Because the primary stiffness is the sum of the primary stiffness of lead rubber bearing and the horizontal stiffness of natural rubber bearing. The primary stiffness of lead rubber bearing is much larger than that of natural rubber bearing with the same diameter. Taking RB500 and 
Article History: Received: 28 October 2021 Revised: 05 December 2021 Accepted: 10 January 2022 Publication: 28 February 2022

LRB500 as examples, the horizontal stiffness of RB500 is $0.760 \mathrm{kN} / \mathrm{mm}$, while the horizontal stiffness of LRB500 before yield is $10.075 \mathrm{kN} / \mathrm{mm}$, which is as much as 12 times. The secondary stiffness of the isolation layer is the sum of the secondary stiffness of the lead rubber bearing and the horizontal stiffness of the natural rubber bearing. After the lead core yields, it does not provide horizontal stiffness, which is equivalent to that only the natural rubber bearing provides horizontal stiffness. The horizontal stiffness of rubber bearings with the same diameter is basically the same, so the secondary stiffness is basically the same. According to the test conditions and reusability, steel beams are used at the upper and lower ends of the test piece, which can fix the connector and mortar formwork. The mortar is provided by two wall panel manufacturers, namely Jianhua wall panel dry mixed mortar and gorgeous wall panel binder. During the wind bearing capacity test of fabricated enclosure structure specimens, according to the standard for test methods of basic performance of building mortar, each group of cube specimens shall be tested for cube compressive strength at the same time.

The specific arrangement of the two connection modes of the wallboard is as follows: the first connection mode is upper connection and lower cushion, that is, one side of the wallboard is connected with the steel beam through the steel U-clamp connector and bolts. The other side shall be bonded with the special dry masonry mortar provided by the manufacturer. The second connection mode is up-down connection, that is, one side of the wallboard is connected with the steel beam through the steel U-clamp connector, and the other side is connected with the steel beam through the L-shaped connector.

Before formal loading, check the reliability of the test device and whether all observation instruments work normally. As it is a vertical load, the self weight of the wall panel shall be determined as the first level load before loading. The self weight of the wall shall be calculated respectively according to the surface density of the test specimen measured by the test side of the cooperative unit Beijing Institute of building engineering in this paper.

Before loading, snap the weight placement reference line on the loading surface of the test piece with an ink line in advance, and determine the loading sequence in different areas to ensure that it is as close to the uniformly distributed load as possible. When loading, it shall be placed according to the datum line.

Although normalized seismic waves are used, the seismic response of structures is still closely related to the type and intensity of seismic waves. In order to accurately explain the seismic response characteristics of the structure and avoid too large dispersion of the time history analysis results, the data processing adopts the method of calculating the mean value of six waves, and the seismic wave intensity adopts 8.5 degree frequent and rare. The evaluation principle of the parameters of the isolation layer: the displacement of the isolation layer in case of double control large earthquake and the shear force of the isolation layer in case of small earthquake. 


\section{CONCLUSION}

In recent years, there are more and more high-rise isolated buildings at home and abroad, and there are more and more requirements for isolation theory and technology. However, there are many deficiencies in the limit value of structure height width ratio, seismic prediction theory of isolated structure and parameter setting of isolation layer, which bring many problems to engineering design. In this paper, the related contents of isolated structure are studied from the fields of mechanical model of isolated bearing - limit value of height width ratio - seismic response prediction based on energy method - parameter analysis of isolated layer and so on. Combined with the research content of this paper, future research can be carried out from the following aspects: Due to the great diversity of seismic waves, the seismic response of structures is greatly affected by seismic waves. In the future, we should standardize the seismic input energy, establish a standard velocity spectrum, and evaluate the seismic response of structures with velocity time history. Study the prediction model of setting viscous damper in the isolation layer, further consider the energy consumption of the superstructure, establish a new parameter prediction model of the isolation layer, and then study the seismic response of the superstructure. By optimizing the parameters of the isolation layer, the optimal yield force coefficient of lead damper under different intensities is established; Then the parameters of isolation layer under viscous damper are studied to provide theoretical support for engineering practice.

\section{ACKNOWLEDGEMENTS}

This research was supported by National Programs for Science and Technology Development of Henan Province, China (Grant No. 212102310972), Key Research Program of Higher Education Institutions of Henan Province, China (Grant No. 20B560016).

\section{REFERENCES}

1. Yuan Yingshu, Jia Fuping, Cai Yue. Structural Performance Degradation Model of Corroded Reinforced Concrete Beams. Acta Civil Engineering, 2001, 34 (003): 47-52

2. Ye Lieping, Lu Xinzheng, Ma Qianli. Seismic Nonlinear Analysis Model, Method and Example of Concrete Structure. Engineering Mechanics, 2006, 23 (0z2): 131-140

3. Ma Huaifa, Chen Houqun, Li Baokun. Numerical Simulation of Mesostructure of Concrete Specimen. Acta Hydrologica Sinica, 2004, 35 (10): 27-35

4. Pichler, B., Hellmich, C. Upscaling quasi-brittle strength of cement paste and mortar: A multi-scale engineering mechanics model. Cement and Concrete Research, 2011, 41:467-476

5. Iskhakov, T., Timothy, J.J., Meschke, G. Expansion and deterioration of concrete due to ASR: Micromechanical modeling and analysis. Cement and Concrete Research 2019, 115: 507-518 
Article History: Received: 28 October 2021 Revised: 05 December 2021 Accepted: 10 January 2022 Publication: 28 February 2022

6. Göbel, L., Lahmer, T., Osburg, A. Uncertainty analysis in multiscale modeling of concrete based on continuum micromechanics. European Journal of Mechanics-A/Solids 2017, 65: 14-29

7. Zhu Bofang. Implicit Method for Creep Stress Analysis of Concrete Structures. Acta Hydrologica Sinica, 1983, 5: 42-48

8. Nie Jianguo, Yu Zhiwu. Research and Application of Steel-concrete Composite Beams in China. Acta Civil Engineering, 1999, 32 (2): 3-8

9. Zhou Junsheng, Lou Zhuanghong. Present Situation and Development Trend of Long Span Prestressed Concrete Continuous Rigid Frame Bridge. Acta Highway Sinica, 2000, 13 (1): 9-13

10. Lu Xilin, Lu Weidong. Experimental Study on Seismic Behavior of Concrete Filled Steel Tubular Columns Under Cyclic Loading. Acta Architectural Structures, 2000 (2):12-19

11. Jiang Chuanliang, Xian Qiaoling. Nonlinear Finite Element Analysis of Reinforced Concrete Structures. Science and Technology and Engineering, 2005, 5 (017): 1323-1324

12. Mathern, Alexandrea,b, Yang, Jinchengc. A practical finite element modeling strategy to capture cracking and crushing behavior of reinforced concrete structures(Article). Materials, 2021, 14(03): 126

13. Niu Bin. Analysis of Flexural Behavior of Externally Prestressed Concrete Beams. Acta Civil Engineering, 1999 (04): 37-44

14. Cai Shaohuai. The Latest Development of Concrete Filled Steel Tubular Structure Technology in China. Acta Civil Engineering, 1999, 32 (004): 16-26 